\title{
GENERAL SURGERY
}

\section{Where are general surgeons located in South Africa?}

\author{
A J Dell, D Kahn \\ Department of Surgery, University of Cape Town Health Sciences Faculty, Groote Schuur Hospital, Observatory, Cape Town, \\ South Africa
}

Corresponding author: Dr A.J. Dell (angelajdell@gmail.com)

Background: Human resources are the backbone of health-care delivery systems and the lack of surgical workforce in developing countries is often the greatest challenge to providing surgical care. The workforce availability and composition is an important indicator of the strength of the health system. This study aimed to analyse the distribution of general surgeons within South Africa.

Methods: A descriptive analysis of the general surgical workforce in South Africa was performed. The total number of specialist and non-specialist general surgeons working in the public sector in South Africa was documented between the periods from the 1 October 2014 until 31 December 2014.

Results: There were significant disparities in the number and distribution of general surgeons in South Africa. There were 1.78 specialist general surgeons per 100 000, of which 0.69 per 100000 specialist general surgeons were working in the public sector. There were 2.90 non-specialist general surgeons per 100000 . There were 6 specialist general surgeons per 100000 insured population working in the private sector, which is comparable with the United States (US). Urban provinces such as Gauteng, the Western Cape and KwaZulu-Natal had the largest number of specialist general surgeons per 100000. These areas had the largest number of medical aid beneficiaries and nearly $60 \%$ of specialist general surgeons were estimated to work exclusively in the private sector.

Conclusion: There was a major shortage of surgical providers in South Africa, and in particular the public sector.

Key Words: Global surgery, Surgical Resources, General surgeons

S Afr J Surg 2018;56(1)

http://dx.doi.org/10.17159/2078-5151/2018/v56n1a2393

\section{Background}

Surgery has been neglected, despite the obvious effect of surgical illnesses on morbidity and mortality. Surgical conditions lead to premature death and disability resulting in a massive economic burden which, if left unmanaged, could cripple the global economy. Greater attention should be given to surgical services, because of the clear evidence of its cost-effectiveness. ${ }^{1-3}$ The full extent of the global burden of surgical disease is largely unknown. Unfortunately, surgical services are not accessible to many of those who need it most. An estimated 2 billion people lack access to the most basic surgical care. ${ }^{4}$ The Lancet Commission estimates this figure could be as high as 5 billion people. ${ }^{5}$ It has been stated that "Africa has less than 3\% of the healthcare workers, $1 \%$ of the surgical workforce and bears nearly $25 \%$ of the burden of surgical disease." ${ }^{6,7}$ Funk et al. estimated that across 23 Lower Middle Income Countries (LMICs), the ratio of general surgeons per population ranged from 0.13 to 1.57 per $100000,8,9$ and the ratio of anaesthetists per population ranged from 0 to 4.9 per $100000 .{ }^{10}$ In contrast, the US had 9 general surgeons and 11.4 anaesthetists per $100000 .{ }^{11}$ Other older studies show a ratio of 1 surgeon per 100000 in sub-Saharan Africa and 5.7 general surgeons per 100000 in the US. ${ }^{12}$ One of the key objectives of the Lancet Commission on Global Surgery was to promote surgery within the global health agenda. A thorough assessment of the surgical workforce density was one of the proposed Lancet indicators. This study aimed to analyse the distribution of general surgeons within South Africa.

\section{Materials and methods}

\section{Study design and data collection}

This was a descriptive analysis of the surgical workforce in South Africa. The total number of specialist general surgeons as well as non-specialist general surgeons were documented for all public hospitals in South Africa. All public hospitals were contacted telephonically and via email, and the number of employed general surgeons requested. Public hospitals 
included all district, regional and tertiary hospitals in the nine provinces. Clinics and so-called specialised hospitals such as psychiatric, tuberculosis (TB) and rehabilitation facilities were excluded based on the assumption that limited or no surgery occurred at these facilities. A list of all hospitals in South Africa was obtained from the provincial health departments and cross referenced with electronic databases of hospitals in South Africa. These were crossreferenced with the National Health Department hospital list from the office of the Minister of Health. Public hospitals were categorised as district level, regional level and tertiary or national central facilities (level 3), based on services they provided. District level hospitals are staffed by generalists and have access to basic diagnostic and therapeutic services. Regional hospitals provide care requiring the intervention of specialists. Tertiary and central hospitals (level 3) provide sub-specialist support to a number of regional hospitals. Hospitals were contacted during the period from 1 October 2014 to 31 December 2014.

The Health Professions Council of South Africa (HPCSA) database as well as national and provincial databases were used to determine the number of registered specialist general surgeons. This was cross-referenced with the College of Medicine of South Africa (CMSA) database, as well as the National census data from the most recent National Population census in 2011. In addition, Professor Martin Veller provided unpublished data from a study which investigated the number of general surgeons.

\section{Variables and characteristics measured}

General surgery is a discipline which requires knowledge of and responsibility for the preoperative, operative and postoperative management of patients with a broad spectrum of diseases, including those which may require nonoperative, elective or emergency surgical treatment. Surgeons working in the public sector were included in this study and the difference between the total number of registered surgeons (HPCSA) and those in the public sector were presumed to be working full-time in the private sector. Most surgeons in public hospitals tended to work only at the hospital of their primary appointment. However, some surgeons worked in private hospitals in addition to their public sector commitments. Specialist (SP) general surgeons were defined as those having completed training and registration through the CMSA. The non-specialist (NSP) general surgeon was defined as any medical officer, registrar or post-intern level doctor performing general surgical procedures (major or minor cases). These doctors perform an important function in South Africa as well as in other under-developed countries, and are responsible for a significant part of the surgical service including common general surgical procedures such as laparotomy, amputations and hernia repair. The ability to perform a caesarean section was not included as a general surgical procedure and these doctors were excluded from the study as this was a measure of the obstetric service provision. Similarly, fracture fixation was part of the orthopaedic care provision. Registrars (residents) were included in the NSP group based on their skill level and surgical decision making capabilities.

\section{Data Analysis}

The captured variables were entered into a Microsoft Excel (2013) spreadsheet. Specialist and non-specialist general surgeon numbers were analysed according to province as well as population number in order to calculate surgeon density. Population numbers were obtained from Statistics South Africa (Stats SA). ${ }^{13}$ A comparison was performed between local provinces and districts as well as with other countries.

\section{Ethics}

Permission to conduct research was obtained from the Department of Health in each province as well as from hospitals. This research was approved by the Human Research and Ethics Committee at the University of Cape Town (HREC 515/2013, 515/2014, 515/2015) and the Departmental Research Council for the Department of Surgery.

\section{Results}

\section{Overview of national results}

There were 327 public hospitals included in the study, 257 (79\%) were district level hospitals, 49 (15\%) were regional level hospitals and $21(6 \%)$ were central and tertiary hospitals (9 central hospitals and 12 tertiary hospitals). These were grouped together during analysis. There was an average of 0.1 specialist general surgeons and three non-specialist general surgeons working in the district hospitals. The regional hospitals had an average of two specialist general surgeons and five non-specialist general surgeons. The tertiary/central hospitals had an average of 12 specialist general surgeons and 21 non-specialist general surgeons.

\section{Number of general surgeons}

There were 894 specialist general surgeons who were registered with the HPCSA in 2014. The various databases showed differing numbers but with cross-referencing of HPCSA, CMSA and Medpages as well as unpublished data (Professor Veller), the final numbers were reached.

Most surgeons are located in the metropolitan areas of Gauteng (GP), the Western Cape (WC) and KwaZulu-Natal (KZN).

Of the 894 registered general surgeons, 376 were working full-time in public hospitals (with or without limited private practice). There were 1587 non-specialist surgeons (registrars and medical officers) performing general surgical procedures, resulting in a total of 1963 general surgeons (specialist and non-specialist) working in the public sector, and 2481 general surgeons in total (Table 1). Figures 1 and 2 demonstrate the number of specialist and non-specialist general surgeons working in public hospitals according to district municipality. 
Table 1. General surgeon number working in public hospitals according to province.

\begin{tabular}{lccccc}
\hline Province & $\begin{array}{c}\text { Specialist general } \\
\text { surgeons registered } \\
\text { in province }\end{array}$ & $\begin{array}{c}\text { Specialist general } \\
\text { surgeons working in } \\
\text { public hospitals }\end{array}$ & $\begin{array}{c}\text { Non-specialist } \\
\text { surgeons working } \\
\text { public hospitals }\end{array}$ & $\begin{array}{c}\text { Total specialist } \\
\text { and non-specialist } \\
\text { general surgeons in } \\
\text { public hospitals }\end{array}$ & $\begin{array}{c}\text { Proportion of } \\
\text { specialists in relation } \\
\text { to total (\%) }\end{array}$ \\
\hline WC & 209 & 77 & 256 & 333 & 23.1 \\
GP & 298 & 158 & 349 & 507 & 31.1 \\
FS & 60 & 14 & 90 & 104 & 13.5 \\
KZN & 203 & 68 & 249 & 317 & 21.5 \\
NC & 10 & 5 & 52 & 57 & 8.7 \\
EC & 53 & 29 & 190 & 121 & 13.2 \\
NW & 22 & 14 & 107 & 94 & 11.6 \\
MP & 23 & 5 & 89 & 211 & 5.3 \\
LP & 16 & 6 & 205 & 1963 & 2.8 \\
Total & 894 & 376 & 1587 & 19.1 \\
\hline
\end{tabular}

*Western Cape (WC), Gauteng (GP), Free State (FS), KwaZulu-Natal (KZN), Northern Cape (NC), Eastern Cape (EC), North West (NW), Mpumalanga (MP), Limpopo (LP)

\section{Number of general surgeons (specialist and non- specialist) per 100000}

The number of general surgeons relative to the population is shown in Table 2. There were a total of 894 registered specialist general surgeons serving a population of 54 million people in South Africa, i.e. 1.78 per 100 000. The highest number of registered specialist general surgeons per 100000 population were in WC (3.41), GP (2.30), FS (2.15) and KZN (1.89).

The number of specialist general surgeons working in public hospitals per 100000 was 0.69 . The WC and GP had the largest number of specialist general surgeons per population working in the public sector, whereas MP and LP had the fewest.

The number of non-specialist surgeons per population working in public hospitals in South Africa, was 2.90 per 100 000. Interestingly, NC (4.46), WC (4.18) and LP (3.64) had the largest number of non-specialist surgeons per 100000 population working in public hospitals.

There were 3.58 specialist and non-specialist surgeons per 100000 population working in public hospitals. The WC (5.44) and NC (4.89) had the largest number and MP (1.88) the smallest number of specialist and non-specialist surgeons per population working in public hospitals.

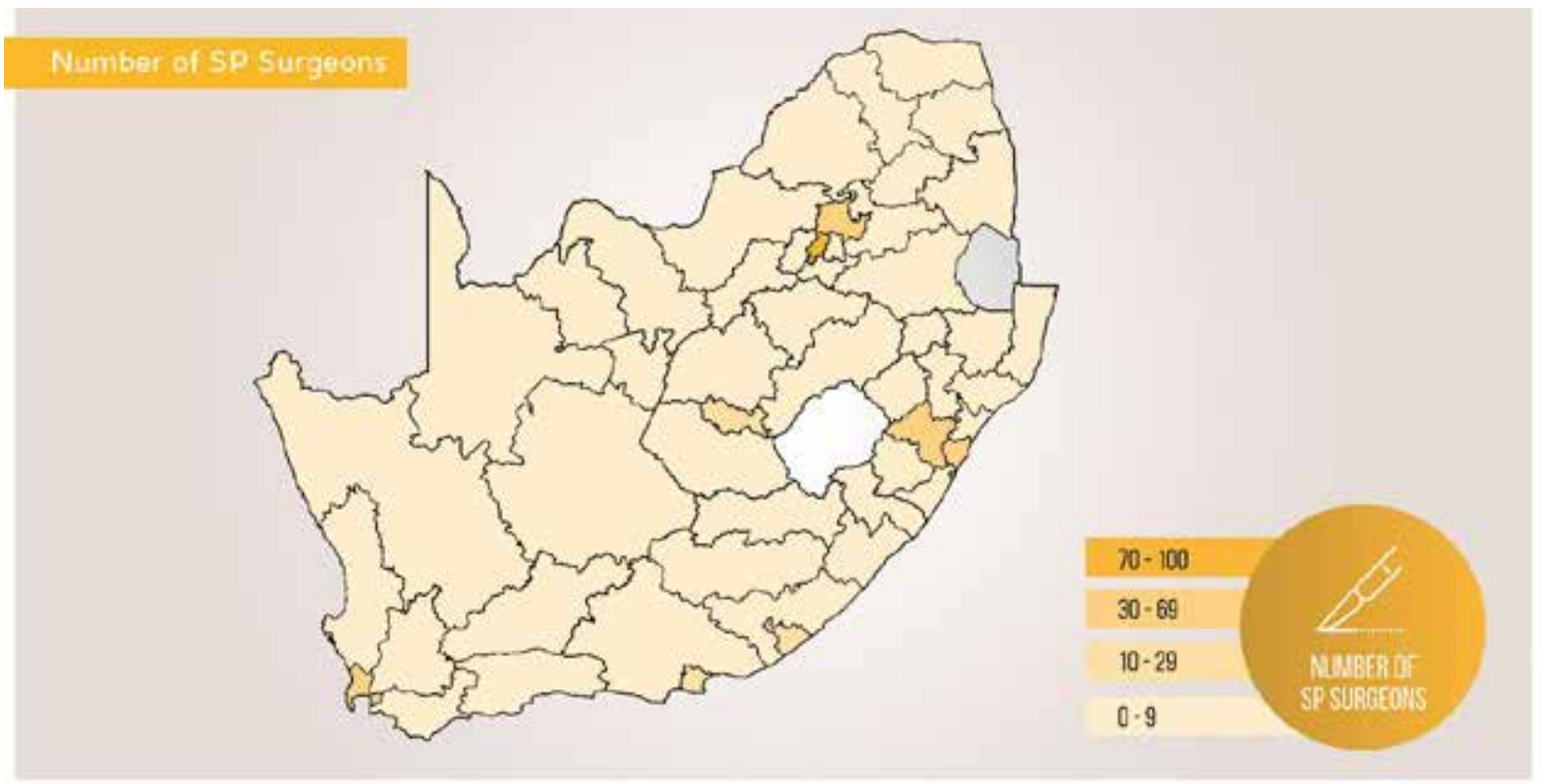

Figure 1. Number of specialist general surgeons (in public hospitals) according to district municipality 


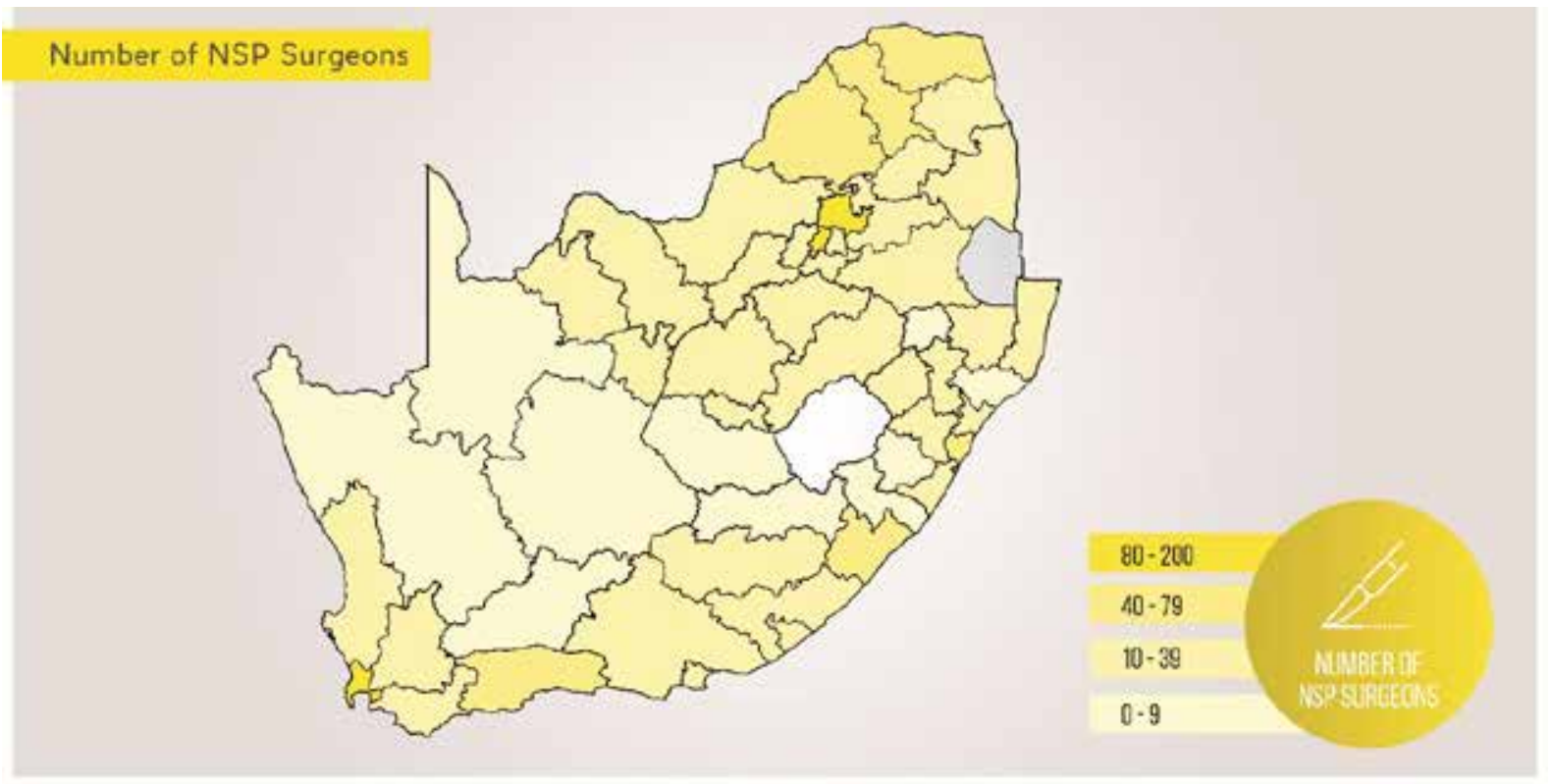

Figure 2. Number of non-specialist general surgeons according to district municipality

\begin{tabular}{|c|c|c|c|c|c|}
\hline Province & Population & $\begin{array}{c}\text { Registered SP per } \\
100000\end{array}$ & $\begin{array}{c}\text { SP working in } \\
\text { public hospitals per } \\
100000\end{array}$ & $\begin{array}{l}\text { NSP working in } \\
\text { public hospitals per } \\
100000\end{array}$ & $\begin{array}{c}\text { Total general } \\
\text { surgeons working } \\
\text { in public hospitals } \\
\text { per } 100000\end{array}$ \\
\hline WC & 6116300 & 3.41 & 1.26 & 4.18 & 5.44 \\
\hline GP & 12914800 & 2.30 & 1.22 & 2.70 & 3.93 \\
\hline FS & 2786800 & 2.15 & 0.50 & 3.23 & 3.73 \\
\hline $\mathrm{KZN}$ & 10694400 & 1.89 & 0.64 & 2.33 & 2.96 \\
\hline $\mathrm{NC}$ & 1166700 & 0.85 & 0.42 & 4.46 & 4.89 \\
\hline $\mathrm{EC}$ & 6786900 & 0.78 & 0.43 & 2.80 & 3.22 \\
\hline NW & 3676300 & 0.60 & 0.38 & 2.91 & 3.29 \\
\hline MP & 4999300 & 0.46 & 0.10 & 1.78 & 1.88 \\
\hline LP & 5630500 & 0.30 & 0.11 & 3.64 & 3.75 \\
\hline Total & 54772000 & 1.78 & 0.69 & 2.90 & 3.58 \\
\hline
\end{tabular}

*Western Cape (WC), Gauteng (GP), Free State (FS), KwaZulu-Natal (KZN), Northern Cape (NC), Eastern Cape (EC), North West (NW), Mpumalanga (MP), Limpopo (LP)

The majority of specialist general surgeons $(65.6 \%)$ worked in central hospitals, which were located in metropolitan areas. Of the specialist general surgeons, only $28 \%$ worked in the regional hospitals and even fewer (7\%), worked at the numerous district level hospitals (Table 3). Conversely, nonspecialist general surgeons worked predominately at district hospitals $(54.5 \%)$. Nearly one third (28.6\%) of non-specialist general surgeons worked at central hospitals, along with the majority of specialist general surgeons, leaving the regional hospitals without a strong surgical workforce (Table 4).

An estimated $42 \%$ of registered specialist general surgeons worked in public hospitals. The smallest proportion of specialist general surgeons working in public practice were in MP $(21.73 \%)$, whereas the largest proportion were in NW (63.63\%) (Table 5).

Approximately $16 \%$ of South Africans had medical insurance. ${ }^{14}$ There were 518 specialist general surgeons working in private hospitals, serving nearly 8.64 million people (6.00 per 100 000). Nearly $58 \%$ of registered specialists were thought to be working in private hospitals. These excluded specialists who were working in the private sector with limited private practice. More than three-quarters of specialist general surgeons worked in the private sector in MP and FS. 
Table 3. Specialist general surgeons according to hospital level

\begin{tabular}{|c|c|c|c|}
\hline Province & District hospital & Regional hospital & Central hospital \\
\hline $\mathrm{EC}$ & 1 & 0 & 28 \\
\hline FS & 0 & 9 & 5 \\
\hline GP & 2 & 27 & 129 \\
\hline KZN & 0 & 46 & 22 \\
\hline LP & 1 & 2 & 3 \\
\hline MP & 0 & 1 & 4 \\
\hline $\mathrm{NC}$ & 1 & 4 & 0 \\
\hline NW & 8 & 6 & 0 \\
\hline WC & 10 & 11 & 56 \\
\hline RSA & 23 & 106 & 247 \\
\hline Proportion of total (\%) & 7.4 & 28.2 & 65.6 \\
\hline
\end{tabular}

Table 4. Non-specialist general surgeons according to hospital level

\begin{tabular}{lccc}
\hline Province & District hospital & Regional hospital & Central hospital \\
\hline EC & 115 & 6 & 69 \\
FS & 52 & 16 & 22 \\
GP & 62 & 75 & 212 \\
KZN & 161 & 73 & 15 \\
LP & 167 & 8 & 30 \\
MP & 67 & 12 & 10 \\
NC & 45 & 7 & 0 \\
NW & 57 & 50 & 0 \\
WC & 140 & 20 & 96 \\
RSA & 866 & 267 & 454 \\
\hline Proportion of total $(\%)$ & 54.6 & 16.8 & 28.6
\end{tabular}

Table 5. Proportion of specialist general surgeons working in public hospitals

\begin{tabular}{lccccc}
\hline Province & $\begin{array}{c}\text { SP registered in } \\
\mathbf{2 0 1 4}\end{array}$ & $\begin{array}{c}\text { SP working in } \\
\text { public hospitals }\end{array}$ & $\begin{array}{c}\text { Proportion of SP } \\
\text { working in public } \\
\text { hospitals (\%) }\end{array}$ & $\begin{array}{c}\text { Estimated number } \\
\text { of SP working in } \\
\text { private hospitals }\end{array}$ & $\begin{array}{c}\text { Proportion of SP } \\
\text { working in private } \\
\text { hospitals (\%) }\end{array}$ \\
\hline WC & 209 & 77 & 36.8 & 132 & 63.2 \\
GP & 298 & 158 & 53.0 & 140 & 47.0 \\
FS & 60 & 14 & 23.3 & 46 & 76.7 \\
KZ & 203 & 68 & 33.5 & 5 & 66.5 \\
NC & 10 & 5 & 50.0 & 24 & 50.0 \\
EC & 53 & 29 & 54.7 & 63 & 45.3 \\
NW & 22 & 14 & 21.7 & 18 & 36.3 \\
MP & 23 & 5 & 37.5 & 10 & 78.3 \\
LP & 16 & 6 & 42.1 & 518 & 62.5 \\
Total & 894 & 376 & & 57.9 & \\
\hline
\end{tabular}

*Western Cape (WC), Gauteng (GP), Free State (FS), KwaZulu-Natal (KZN), Northern Cape (NC), Eastern Cape (EC), North West (NW), Mpumalanga (MP), Limpopo (LP) 


\section{Discussion}

Human resources are the backbone of health-care delivery systems and the lack of human resources in developing countries is often the greatest challenge to providing surgical care. Simply funding and providing equipment will not completely address the surgical disparities which exist between low (LIC) and high income countries (HIC) and understanding a country's baseline surgical and anaesthetic capacity is critical to improving the quality of services and outcomes. The lack of surgical infrastructure results in fewer surgeries being performed, which results in delays to treatment and often more resource intensive surgery for pathologies such as advanced malignancies.

There were significant disparities in the number and distribution of general surgeons in South Africa. There were 1.78 specialist general surgeons per 100000 , of which 0.69 specialist general surgeons per 100000 were working in the public sector. There were 2.90 non-specialist general surgeons per 100 000. As expected, urban provinces such as Gauteng, the Western Cape, KwaZulu-Natal as well as the Free State had the largest number of specialist general surgeons per 100000 . These areas had the largest number of medical aid beneficiaries and as demonstrated, nearly $60 \%$ of specialist general surgeons work exclusively in the private sector.

The largest number of specialist surgeons per population were in the Western Cape and Gauteng. Limpopo and Mpumalanga had the fewest surgeons per population with approximately 0.30 per 100000 respectively. Approximately $16 \%$ of South Africans had medical insurance. This meant that 518 specialist general surgeons who worked in the private sector served nearly 8.64 million people $(6.00$ per 100000$)$, which is comparable with HICs such as the US.

The majority $(65 \%)$ of specialist surgeons were working at level three or central hospitals in urban areas, with $28 \%$ working at regional hospitals, and only $7 \%$ working at district level facilities. Non-specialist surgeons were predominately located at district level hospitals (54\%) and tertiary hospitals (28\%), whereas $16 \%$ were located at regional hospitals. An assessment of surgery at South African district hospitals demonstrated that the volume of surgeries being undertaken was low, and that almost no abdominal surgeries were performed..$^{15}$ A letter published in the World Journal of Surgery highlighted the limited role which specialist surgeons play at district level hospitals because of the need for ancillary services. ${ }^{16}$ The objective should be to provide adequate surgical expertise at the district level, without the use of specialised level three investigations and services.

There were a large number of non-specialist general surgeons located throughout the country. They contribute significantly to managing the burden of surgical disease. They have no formal specialist qualification although many are extremely experienced surgically. Non-specialist surgeons were the only surgical providers in $65 \%$ of hospitals in South Africa, demonstrating their importance in the provision of surgical care. They comprised $64 \%$ of the general surgical workforce. This important information on the current state of surgical providers cannot be overemphasised. There is also a large contingency of senior general surgeons from countries such as Cuba, who have not written the South African College examinations but who are viewed as senior surgeons. They were not included in the specialist surgical group and this is a limitation in the way data was collected and reported. In addition, registrars who will progress to become specialist general surgeons were included in the non-specialist group. Registrar numbers skewed the data around training regions, however specialist surgeons also tended to remain in urban areas, which further affected the results.

When specialist and non-specialist surgeons were combined, $45 \%$ were found to be working at district level hospitals, $19 \%$ at regional level hospitals and $36 \%$ at central level hospitals. This suggested that the regional level hospitals had a limited surgical workforce which is inadequate to deal with the surgical burden of disease. Regional level hospitals often bear the brunt of the referral system as they drain large numbers of patients from district level facilities. The regional hospitals are expected to manage many surgical conditions and often experience difficulty referring to central hospitals, as these facilities have large drainage areas and need to transfer patients back once stabilised.

There were provincial differences in the proportion of specialist surgeons working in the public hospitals. Mpumalanga had the smallest proportion of its specialist general surgeons working in public hospitals $(21 \%)$, which along with provinces such as the Western Cape, Limpopo, Free State and KwaZulu-Natal were fewer than the national average of $42 \%$. Gauteng, the Northern Cape, the Eastern Cape and the North West had between $50 \%$ and $63 \%$ of specialist surgeons working in public sector hospitals. Apart from Gauteng, these provinces were rural, which might explain why a larger proportion worked in public hospitals. With fewer surgeons working in these provinces and with a smaller number of private hospitals, more surgeons are available to work in the public sector. More than threequarters of specialist general surgeons worked in the private sector in Mpumalanga and the Free State.

In South Africa, an estimated 7000 medical specialists work in the private sector compared with 4000 that work in the public sector. ${ }^{17}$ It was very difficult to obtain accurate data on how many surgeons were working in the private sector since surgeons often work at more than one private facility. However, we know the total number of registered specialist surgeons $(n=894)$ and the number working in public hospitals $(\mathrm{n}=376)$. It can be presumed that the remaining surgeons were working in private facilities in South Africa.

Surgical workforce maps demonstrate workforce density per geographical area, as well as trends over time. Surgical workforce mapping allows surgeons who are considering setting up practice, to answer questions around practice realities and locations. Surgical maps are of equal value to patients who can determine where surgical access is readily available. Upgrading of current workforce databases to include electronic mapping capabilities needs to be considered 
as a matter of urgency. Areas of need could be identified and may be used to highlight where surgeons are most needed.

\section{Worldwide comparison}

South Africa had 1.78 specialist general surgeons per 100 000. In comparison, HICs such as the US had 7 per 100000 and as many as 30 per 100000 in the UK. LMICs have between 0.3 and 0.55 surgeons per 100000 , whereas LICs have $0.05-0.3$ per $100000 .{ }^{18-20}$ The Lancet Commission on Global Surgery estimated that around $12 \%$ of specialists in HICs graduated from medical schools in LMICs, indicating a cycle of emigration, strain on residual workforce and further emigration. ${ }^{5}$ It is common-place for South African surgeons to further their surgical training abroad through fellowship programmes, which could take a year or more to complete. Some of these surgeons are offered permanent employment and residency in these countries. The challenge would be to encourage further training in developed countries, but to incentivise their return after completion.

\section{Limitations}

The Lancet commission recommended quantifying the surgical, anaesthetic and obstetric workforce and as this study only assessed general surgeons, the remaining indicators still need to be quantified in South Africa. Sub-specialist general surgical disciplines such as vascular surgeons, endocrine surgeons, colorectal surgeons, hepatobiliary surgeons and trauma surgeons were included but no sub-analysis was performed. Specialist surgeons were difficult to quantify as the HPCSA provincial and national databases differed. It was not clear whether surgeons were registered using their home address or practice addresses, and therefore quantifying surgeons according to district was inaccurate. The only means of determining the number was to assess the number of specialists working at public hospitals, as they are usually contracted to work in a single facility. An attempt was initially made to quantify specialist surgeons working at private hospitals, but this was abandoned as a single surgeon would work at more than one private facility. Specialists working in the public sector who undertook limited private practice were not evaluated. When quantifying the non-specialist general surgeon number, only doctors who were able to perform general surgeries such as laparotomies, amputations and hernias were included. If this were not the case, these 'surgeons' were excluded. Further research is needed to quantify surgeons only capable of performing caesarean sections.

\section{Conclusion}

It is necessary to acknowledge the major shortage of healthcare providers. The Department of Health needs to assess workforce numbers and trends in order to achieve a minimum density by 2030 . The surgical burden is significant and the surgical workforce needs to be adequately delineated. Workforce data is dynamic and needs to be assessed annually, with regional trends being evaluated periodically. An integrated electronic database would be the best way forward to allow accurate and periodic assessment of data. Specialist and non-specialist surgeons could be sub-analysed in greater detail which would provide greater information regarding surgical workforce mapping. Training of additional surgical specialists, as well as providing support to nonspecialist surgeons is critical in bridging the workforce gap. Incentivised retention policies aimed at attracting surgeons to geographic areas of need, as well as returning from overseas will need to be explored. Identifying surgical trainees early in their careers, investing in their specialisation and creating additional registrar training posts are means of expanding the workforce. Non-specialist doctors need to be supported and are invaluable in service provision.

\section{REFERENCES}

1. Ozgediz D, Jamison D, Cherian M, McQueen K. The Burden of surgical conditions and access to surgical care in low- and middle-income countries. Bull World Health Organ. Aug 2008;86(8):646-7. doi: 10.2471/BLT.07.050435 PMID: 18797625. PMCID PMC2649455.

2. Bickler S, Ozgediz D, Gosselin R, Weier T, Spiegel D, Hsia $\mathrm{R}$, et al. Key concepts for estimating the burden of surgical conditions and the unmet need for surgical care. World J Surg. 2010;34:372-380. doi: 10.1007/s00268-009-0261-6

3. Luboga S, Galukande M, Mabweijano J, Ozgediz D, Jayaraman S. Key aspects of Health Policy Development to Improve Surgical Services in Uganda. World J Surg. 2010;34:2511-7. doi 10.1007/s00268-010-0585-2

4. Weiser TG, Regenbogen S, Thompson K, Haynes AB, Lipsitz S, Berry W, Gawande A. An estimation of the global volume of surgery: A modelling strategy based on available data. Lancet. 12 Jul 2008;372(9633):139-44. doi: 10.1016/S01406736(08)60878-8. [Epub 2008]

5. Meara JG, Leather AJM, Hagander L, et al. Global surgery 2030: evidence and solutions for achieving health, welfare, and economic development. Lancet. 8 Aug 2015; 386(9993):569624. doi: http://dx.doi.org/10.1016/S0140-6736(15)60160-X

6. McQueen K. Essential Surgery: Integral to the right to health. Health and Human Rights in Practice. 2010 [accessed 20 January 2014];12(1)137-52. Available from: http://www.jstor. org/stable/healhumarigh.12.issue-1

7. Mars M. Chapter 128: Paediatric Surgery Education in subSaharan Africa. In: Paediatric Surgery: A comprehensive text for Africa. pp.783-6. Available from: http://www.global-help. org/publications/books/help_pedsurgeryafrica128.pdf

8. Funk L, Weiser T, Berry W, et al. Global operating theatre distribution and pulse oximetry supply: an estimation from reported data. Lancet. 2010;376:1055-61. doi: 10.1016/S01406736(10)60392-3

9. Mock C, Donkor P, Gawande A. Jamison D, Kruk M, Debas H, editors. Chapter 1 Essential Surgery: Key Messages of this Volume. 2015. In: Disease Control Priorities, Third Edition (Volume 1). Washington DC: The International Bank for reconstruction and Development/ The World Bank. PMID 26741007.

10. Hoyler M, Finlayson S, McClain, Meara J, Hagander L. Shortage of doctors, Shortage of data: A Review of the Global Surgery, Obstetrics and Anaesthesia Workforce literature. World J Surg. 2014;38(2):269-80. doi 10.1007/s00268-013-2324-y 
11. Stewart B, Khanduri P, McCord C, et al. Global Disease Burden of Conditions Requiring Emergency Surgery. Br J Surg. Jan 2014;101(1):e9-22. doi: 10.1002/bjs.9329. [Epub 25 Nov 2013]

12. Lynge $\mathrm{D}$, Larson $\mathrm{E}$, Thompson $\mathrm{M}$, et al. A longitudinal analysis of the general surgery workforce in the United States, 1981-2005. Arch Surg. 2008;143(4):345-50. doi:10.1001/ archsurg.143.4.345

13. Statistics SA Annual 2013/2014 report. [Accessed 20 January 2014]. Available from: www.statssa.gov.za

14. Massyn N, Day C, Peer N, Padarath A, Barron P, English R, editors. District Health Barometer. 2013/2014. Health Systems Trust. Available from: www.hst.org.za/publications/districthealth-barometer-201314

15. Clarke D, Kong V, Handley J, Aldous C. A concept paper: Using the outcomes of common surgical conditions as quality metrics to benchmark district surgical services in South Africa as part of a systematic quality improvement programme. S Afr J Surg. 2013;51(3):84-6. doi: 10.7196/sajs.1476

16. Chu K. Should surgeons work in rural district hospitals in
Africa? World J Surg. 2012;36:935. doi: 10.1007/s00268-011$1368-0$

17. Van der Berg, et al. Financial implications for the National Health Insurance Plan. Commissioned by the HASA. Econex. March 2010 [accessed on 20 January 2014]. Available from: www.hasa.co.za

18. Kakande I, Mkandawire N, Thompson M. A review of surgical capacity and surgical education programmes in The COSECSA Region. East and Central African Journal of Surgery. 2011 [accessed on 13 January 2013];16(3):6-34. Available from: www.bioline.org

19. American College of Surgeons Health Policy Research Institute. The Surgical Workforce in the United States: profiles and recent trends. 2010 [accessed 13 January 2014]. Available from: http:// www.acshpri.org/pubs.html

20. Royal College of Surgeons of England. Surgical Workforce 2011. 2011 [accessed 13 January 2014]. Available from: https:// www.rcseng.ac.uk/surgeons/surgical-standards/docs/2011surgical-workforce-census-report 